\title{
Sri Lanka guidelines for the management of hepatic metastases from colorectal cancer
}

A Joint initiative of the Sri Lanka National Chapter of the International Hepato-Pancreato-Biliary Association (SLHPBA) and the International Hepato-Pancreato-Biliary Association (IHPBA)

Dharmapala $\mathrm{AD}^{1}$, Siriwardena $\mathrm{RC}^{2}$, Chan $\mathrm{A}^{3}$, Adair $\mathrm{A}^{4}$, Shrikhande $\mathrm{S}^{5}$, Jeyarajah $\mathrm{R}^{6}$, Jegatheeswaran $\mathrm{S}^{3}$, Jagannath $\mathrm{P}^{7}$, Siriwardhane $\mathrm{M}^{8}$, Sivaganesh $\mathrm{S}^{9}$, Pathirana $\mathrm{AA}^{10}$, Siriwardena $\mathrm{AK}^{3}$

${ }^{1}$ Department of Surgery, University of Peradeniya, Peradeniya, Sri Lanka

${ }^{2}$ Department of Surgery, University of Kelaniya, Ragama, Sri Lanka

${ }^{3}$ Regional HPB Unit, Manchester Royal Infirmary, Manchester, UK

${ }^{4}$ Department of Transplant Surgery, Edinburgh Royal Infirmary, Edinburgh, UK

${ }^{5}$ Department of Surgical Oncology, Tata Memorial Hospital, Mumbai, India

${ }^{6}$ Methodist Dallas Medical Center, Texas, USA

${ }^{7}$ Lilavati Hospital \& Research Centre, Mumbai, India

${ }^{8}$ Mater Hospital, Raymond Terrace, South Brisbane, Queensland, Australia 4101

${ }^{9}$ Department of Surgery, University of Colombo, Colombo, Sri Lanka

${ }^{10}$ Department of Surgery, University of Sri Jayewardenepura, Nugegoda, Sri Lanka

Key words: Hepatic metastases; colorectal cancer

\begin{abstract}
Guidelines to manage liver metastases were developed at a meeting jointly organized by the Sri Lanka Hepato Pancreato Biliary Association (SLHPBA) and the International Hepato Pancreato Biliary Association (IHPBA). Existing evidence was used in the development of guidelines, as recommended by the AGREE II consortium. Guidelines are provided for diagnosis, pre-operative workup, multi-disciplinary team review, surgery, anaesthesia, post-operative care and follow up. Consideration was given to the limitations of facilities available in the country.
\end{abstract}

\section{Introduction}

Liver resection is indicated in carefully selected patients with hepatic metastases from colorectal cancer [1]. As hepatic surgery has developed as a subspecialty, the skills and expertise required to undertake liver resection and to provide peri-operative care for these patients, have become more widely available. There is good evidence that this type of complex surgery should be concentrated in specialist units . In the current era, clinical decision making should be formulated in a multidisciplinary team.

The collaboration between the Sri Lanka National Chapter of the International Hepato-Pancreato-Biliary Association

\footnotetext{
Correspondence: Professor Aloka Pathirana

E-mail: alokapathi@gmail.com

Received: 27-11-2017 Accepted: 12-12-2018

(iD http://orcid.org/0000-0002-8608-7770

DOI: http://doi.org/10.4038/sljs.v36i4.8554
}

The Sri Lanka Journal of Surgery 2018; 36(4): 20-24
(SLHPBA) and the International Hepato-Pancreato-Biliary Association (IHPBA) started in 2015 and at the last meeting held in Colombo in August 2017, a full day was dedicated to the production of multidisciplinary, disease-specific guidelines. This process led to the publication of the Sri Lanka guidelines for the diagnosis and management of acute pancreatitis [3] and management of hepatocellular carcinoma [4]. As the 2012 revision of the Atlanta consensus document [5] on which the Sri Lanka pancreatitis guidelines were based provides an international reference standard, the process of adapting guidelines was relatively straightforward. There are no similar, universally accepted international guidelines for the management of liver metastases from colorectal cancer. Thus, the aim of this document is to utilise the approach recommended by the AGREE (Appraisal of Guidelines for Research and Evaluation) consortium [6] to adapt international guidelines to Sri Lanka.

The objectives of this guideline are to provide contemporary and practical advice for the management of patients with liver metastases from colorectal cancer within the healthcare system of Sri Lanka.

\section{Methods \\ Adapting existing evidence.}

Aspects of the approach recommended by the AGREE II consortium was adopted [6].

The AGREE II consortium describes a practical method for clinicians to adopt existing evidence and to synthesise guidelines. 
This document uses the following domains of the AGREE II guideline:

1.The scope and purpose of the guideline should be clearly defined.

2.The guideline should involve all stakeholder groups: surgeons, oncologists, radiologists and others with a relevant interest.

3.The guideline should be developed systematically.

4. The guideline should be presented clearly.

5.The guideline should be of practical value.

Guideline development meeting of the SLHPBA/IHPBA global outreach team

The meeting was attended by surgeons, oncologists, pathologists and radiologists from Sri Lanka. The IHPBA team was composed of surgeons from the United Kingdom, the United States of America, India and Australia. The outline presentation on colorectal liver metastases was given by Dr Arinda Dharmapala.

Subsequently, international guidelines from the United States of America [7], the United Kingdom [8], Europe [9] and Japan [10] were reviewed in detail and a draft discussion document was synthesised by Professor Ajith Siriwardena and has been modified over a series of discussions with all stakeholders and co-authors.

The final guidance is given below.

\section{SRI LANKA GUIDELINES}

\section{Diagnosis of hepatic metastases}

\subsection{Imaging}

- Imaging for staging of patients with liver metastases from colorectal cancer should include contrast-enhanced triple-phase computed tomography (CT) of the thorax, abdomen and pelvis.

- Contrast-enhanced magnetic resonance (MR) scanning of the liver provides additional information and is also recommended [11].

- MR imaging should be undertaken at baseline and before chemotherapy, when available.

-18Fluorodeoxyglucose positron emission scanning (FDG-PET) is not routinely available in Sri Lanka at the time of production of this guideline. A large randomised trial has demonstrated no additional survival benefit from the use of FDG-PET as an additional test and thus FDGPET is NOT recomm-ended [12].

\subsection{Blood Tests}

- Baseline blood tests should include full blood count, coagulation profile, urea and electrolytes and enzymatic liver function tests.

- CEA (carcino embryonic antigen) level is useful in follow-up and in assessing response to treatment and should be considered if available [13].

\subsection{Genetic Testing}

- Genetic testing for mutations of the K-ras (Kirsten Rat Sarcoma virus) gene is not widely available. If available, $\mathrm{K}$-ras mutation testing is useful in assessing whether to prescribe biologic chemotherapy agents aimed at inhibiting the EGFR (Epidermal Growth Factor Receptor) pathway [14]. Patients who carry mutations of K-ras are resistant to EGFR-inhibitor therapy [15].

\section{Pre-operative work-up}

2.1 Assessment of cardiac and respiratory fitness for surgery

- In addition to a detailed clinical history and physical examination together with a record of co-morbidities and medication, baseline tests should include a 12-lead electrocardiogram and in those individuals with respiratory disease, pulmonary function tests.

\subsection{Pre-operative risk scores}

- The revised cardiac risk index or the New York Heart Association Functional Class(NYHA) [16] may provide additional information in pre-operative risk assessment.

\section{Multidisciplinary team case review}

\subsection{Composition}

- The multidisciplinary team (MDT) should have represent-ation from all groups involved in the care of patients with metastatic colorectal cancer. The core group should include liver and colorectal surgeons, clinical oncologists, radiologists, pathologists and specialist nurses.

\section{Surgery}

4.1 Treatment goal of liver resection for colorectal hepatic metastases

- Hepatic resection is the treatment of choice for resectable liver metastases.

- Complete resection must be feasible based on anatomical grounds and the extent of disease, with maintenance of adequate hepatic function.

4.2 liver resection in the presence of extrahepatic metastases

- Hepatic resection should not generally be undertaken in the presence of extra-hepatic disease. There may be exceptions to this rule: for example, liver surgery may be considered in patients with small volume, stable lung lesion(s) or in those patients with a solitary lung lesion amenable to resection/ablation or external radiotherapy. 
- It should be remembered that the evidence-base for surgical resection of lung metastases from colorectal cancer is very limited.

\subsection{Modern terminology of liver resections}

- Modern terminology for liver resection uses the terminology outlined in the Brisbane consensus conference and illustrated in a subsequent review article [1].

\subsection{Extent of safe liver resection}

- The principle of safe liver surgery is to ensure adequate inflow, outflow and biliary drainage of the future remnant liver. Thus, a resection of up to $70 \%$ of the liver parenchyma in the form of a right trisection-ectomy or left trisectionectomy can be undertaken.

- The extent of safe resection is reduced by patient factors such as cirrhosis, fatty liver, non-alcoholic fatty liver disease (NAFLD) and increasing age. The extent of safe resection is also reduced by prior chemotherapy. If CT volumetry is available, it should be utilised in resection planning to assess safe future remnant liver.

- If the future remnant liver (FRL) is likely to be too small, portal vein ligation or percutaneous embolization of the portal vein (PVE) - typically the right portal vein - will produce compensatory hypertrophy of the left lobe. In patients undergoing modification of the FRL, baseline CT and follow-up CT at around 4 to 6 weeks should be undertaken.

4.5 Use of prognostic scores to determine whether to offer resection

- It is accepted that the number of liver metastases does not determine resectability. However, prognostic scores such as that developed by Memorial Sloan-Kettering Hospital indicate that patients with more than 5 liver metastases with the largest being $>5 \mathrm{~cm}$ in size, and present within 12 months of presentation of the primary, together with a node positive tumour and high CEA have a high risk of early recurrence [17].

\subsection{Anaesthesia and preparation for liver surgery}

- Patients should have blood cross-matched and available in theatre.

- Peri-operative analgesia can be provided by epidural catheters although there is recent evidence that wound catheters are also effective [18].

- Intra-operative monitoring requires invasive arterial display of heart rate and blood pressure.

- Central venous pressure should be monitored and should be maintained at a low level during liver transection by avoidance of excessive infusion of intravenous fluid.

\subsection{Liver transection}

- It is recommended practice to use intra-operative ultrasonography to confirm the distribution of liver lesions and to confirm that the future remnant liver is disease-free.

- There is a very wide range of liver transection equipment. There is no evidence of superiority for any particular device [19].

- Current evidence suggests that the laparoscopic approach should be offered for patients requiring left lateral sectionectomy [20]. Other resections can be undertaken laparoscopically following the same principles of open liver surgery [21].

4.8 Post-operative care after liver resection.

- Patients should be nursed in a high-dependency unit after surgery with 1:1 nursing care and facilities for inotropic support and non-invasive ventilator support.

- If a surgical drain is used the drain bilirubin should be measured on the 3rd post-operative day.

- The terminology for reporting of complications recommended by the International Study Group for Liver Surgery (ISGLS) should be used [22-24].

\section{Chemotherapy}

- A detailed discussion of chemotherapy is beyond the scope of these guidelines.

- The EORTC 40983 study showed that in patients with up to four metachronous liver metastases, treatment with pre- and post-operative oxaliplatin produced no improvement in 5-year survival compared to surgical resection alone. However, an increase in progression free survival was noted compared with surgery alone [25].

- This study showed no additional morbidity in patients having liver resection after chemotherapy but it should be emphasised that the amount of pre-operative chemotherapy was relatively limited.

- Current evidence indicates that either an oxaliplatinbased or an irinotecan-based chemotherapy backbone can be utilised as first line care in either the neo-adjuvant or adjuvant setting.

- The New-EPOC trial showed no additional survival benefit from adding cetuximab to these chemotherapy regimens although it is now known that cetuximab is only effective in patients who do not carry mutations of K-ras or B-raf [14].

\section{Follow-up}

6.1 Surveillance

- Outpatient follow-up (history and examination) every 6 months for 5 years. 
- CEA at each outpatient appointment

- CT thorax / abdomen / pelvis every 6 months for 2 years, then annually till 5 years.

- Ensure completion colonoscopy.

- Colonoscopy at 1 year.

\section{Newer treatments for colorectal hepatic metastases.}

7.1 Associating Liver Partition and Portal Vein Ligation for Staged Hepatectomy (ALPPS)

- ALPPS is a recognised technique for treatment of hepatic metastases when there is insufficient tumour-free parenchyma to sustain a one-stage resection.

- Although established and supported by an international registry the recent LIGRO randomized trial of ALPPS versus two-stage hepatectomy showed an $8 \%$ mortality associated with ALPPS [26].

- IfALPPS is to be considered, it is recommended that units join the international ALPPS registry.

- At the time of writing of these guidelines, ALPPS remains a technique to be viewed with caution and is as yet unestablished in mainstream liver surgical practice.

\subsection{Ablation of liver tumours}

- Although not strictly a "newer" technique, technical and equipment developments have made ablation a treatment option that may be utilised.

- Ablation involves destruction of liver tumours either by using thermal energy (radiofrequency ablation, microwave ablation) or by using electrical energy to cause cellular destruction (irreversible electroporation - IRE).

- Cryotherapy is no longer utilised for the treatment of colorectal hepatic metastases.

- There is some evidence that ablation can be effective and it may be used in conjunction with resection.

- Advantages of ablation are that it can be used percutaneously. Ablation is currently not a preferred treatment for colorectal hepatic metastases because of the relatively high risk of recurrence.

\section{Treatments of no proven benefit for colorectal hepatic metastases}

8.1 Selective Internal Radiation Therapy (SIRT)

- SIRT involves the angiographic delivery of beads or microparticles incorporating the radio-isotope Yttrium90 to liver tumours.

- Although initially thought to be promising, the pooled analysis of three world-wide randomised trials has shown no evidence of survival benefit [27].

- A valid criticism of these studies was the high proportion of patients with extra-hepatic disease who were subjected to SIRT.
- However, even in the subgroup of patients with liverlimited hepatic metastases treated by SIRT there was neither evidence of survival benefit nor a higher conversion to resection.

- SIRT is now regarded as a treatment of no benefit for patients with colorectal hepatic metastases.

\section{Planned review of guidelines}

- The SLHPBA/IHPBA will review these guidelines in 5 years.

All authors disclose no conflict of interest. The study was conducted in accordance with the ethical standards of the relevant institutional or national ethics committee and the Helsinki Declaration of 1975, as revised in 2000 .

\section{References}

1. Siriwardena AK, Mason JM, Mullamitha S, Hancock HC, Jegatheeswaran S. Management of colorectal cancer presenting with synchronous liver metastases. Nat Rev Clin Oncol 2014; 11:446-459.

https://doi.org/10.1038/nrclinonc.2014.90

2. Dimick JB, Cowan JA, Jr., Knol JA, Upchurch GR, Jr. Hepatic resection in the United States: indications, outcomes, and hospital procedural volumes from a nationally representative database.

Arch Surg. 2003;138(2):185-91.

http://doi.org/10.1001/archsurg.138.2.185

3. Sivaganesh S, Siriwardena A, Pathirana A. SLHPBA guidelines on the management of acute pancreatitis - a consensus document. Sri Lanka Journal of Surgery. 2017; 35:29-33. http://doi.org/10.4038/sljs.v35i4.8436

4. Siriwardena RC, Pathirana AA, Siriwardana AK, Espat NJ, Adair A. SLHPBA Guidelines for the management of hepatocellular carcinoma in Sri Lanka - consensus statement. Sri Lanka Journal of Surgery 2018;36(1): 31-33. http://doi.org/10.4038/sljs.v36i1.8478

5. Banks PA, Bollen TL, Dervenis C, Gooszen HG, Johnson CD, Sarr MG, et al. Classification of acute pancreatitis--2012: revision of the Atlanta classification and definitions by international consensus. Gut. 2013; 62:102-111. http://doi.org/10.1136/gutjnl-2012-302779

6. Brouwers MC, Kho ME, Browman GP, Burgers JS, Cluzeau F, Feder G, et al. AGREE II: advancing guideline development, reporting and evaluation in health care. CMAJ. 2010;182: E83942.https://doi.org/10.1503/cmaj.090449

7. National Comprehensive Cancer Network. Clinical practice guidelines in oncology. Colon Cancer. Version 3.2018. https://www.nccn.org/professionals/physician_gls/pdf/colon.pdf

8. National Institute for Health and Care Excellence. Colorectal cancer diagnosis and management. November 201. https://www.nice.org.uk/guidance/cg131

9. Van Cutsem E, Cervantes A, Adam R, Sobrero A, van Krieken JH, Aderka D et al. ESMO consensus guidelines for the management of patients with metastatic colorectal cancer. Ann Oncol 2016; 27:1386-1422.

https://doi.org/10.1093/annonc/mdw235

10. Watanabe T, Itabashi M, Shimada Y, Tanaka S, Ito Y, Ajioka Y et al. Japanese Society for Cancer of the Colon and Rectum (JSCCR) Guidelines 2014 for treatment of colorectal cancer. Int J Clin Oncol 2015 20:207-239. http://doi.org/10.1007/s10147-015-0801-z 
11.Blyth S, Blakeborough A, Peterson M, Cameron IC, Majeed AW. Sensitivity of magnetic resonance imaging in the detection of colorectal liver metastases. Ann R Coll Surg Engl. 2008; 90:2528. http://doi.org/10.1308/003588408X242303

12. Moulton CA, Gu CS, Law CH, Tandan VR, Hart R, Quan D, et al. Effect of PET before liver resection on surgical management for colorectal adenocarcinoma metastases: a randomized clinical trial. JAMA. 2014;311(18):1863-1889

. http://doi.org/10.1001/jama.2014.3740

13. Berman JM, Cheung RJ, Weinberg DS. Surveillance after colorectal cancer resection. Lancet. 2000; 355:395-399. https://doi.org/10.1016/S0140-6736(99)06552-6

14. Primrose J, Falk S, Finch-Jones M, Valle J, O'Reilly D, Siriwardena A, et al. Systemic chemotherapy with or without cetuximab in patients with resectable colorectal liver metastasis: The New EPOC randomised controlled trial. Lancet Oncol. 2014; 15:601-611. http://doi.org/10.1016/S1470-2045(14)70105-6

15. Misale S, Yaeger R, Hobor S, Scala E, Janakiraman M, Liska D, et al. Emergence of KRAS mutations and acquired resistance to anti-EGFR therapy in colorectal cancer. Nature. 2012; 486:532536. http://doi.org/10.1038/nature11156

16. The Criteria Committee of the New York Heart Association. Nomenclature and Criteria for Diagnosis of Diseases of the Heart and Great Vessels. 9th ed. Boston, Mass: Little, Brown \& Co; 1994:253-256. https://trove.nla.gov.au/version/13288061

17. Fong Y, Fortner J, Sun RL, Brennan MF, Blumgart LH. Clinical Score for Predicting Recurrence After Hepatic Resection for Metastatic Colorectal Cancer Analysis of 1001 Consecutive Cases. Ann Surg 1999; 230:309-321. https://www.ncbi.nlm.nih.gov/pmc/articles/PMC1420876/

18. Revie EJ, McKeown DW, Wilson JA, Garden OJ, Wigmore SJ. Randomized clinical trial of local infiltration plus patientcontrolled opiate analgesia vs. epidural analgesia following liver resection surgery. HPB (Oxford). 2012; 14:611-618. http://doi.org/10.1111/j.1477-2574.2012.00490.x

19. Appéré F, Piardi T, Memeo R, Lardière-Deguelte $S$, Chetboun $M$, Sommacale D, Pessaux P, Kianmanesh R. Comparative Study with Propensity Score Matching Analysis of Two Different Methods of Transection During Hemi-Right Hepatectomy: Ultracision Harmonic Scalpel Versus Cavitron Ultrasonic Surgical Aspirator. Surg Innov 2017; 24:499-508. http://doi.org/10.1177/1553350617723269

20. Chang S, Laurent A, Tayar C, Karoui M, Cherqui D Laparoscopy as a routine approach for left lateral sectionectomy. Br J Surg 2007; 94:58-63.

https://www.ncbi.nlm.nih.gov/pubmed/17054316
21. Wakabayashi G, Cherqui D, Geller DA, Buell JF, Kaneko H, Han $\mathrm{HS}$ et al. Recommendations for laparoscopic liver resection. A report from the second international consensus conference held in Morioka. Ann Surg 2015;261:619-629. PMID: 25742461

22. Koch M, Garden OJ, Padbury R, Rahbari NN, Adam R, Capussotti L, et al. Bile leakage after hepatobiliary and pancreatic surgery: a definition and grading of severity by the International Study Group of Liver Surgery. Surgery. 2011;149(5):680-688. http://doi.org/10.1016/j.surg.2010.12.002

23. Rahbari NN, Garden OJ, Padbury R, Brooke-Smith M, Crawford M, Adam R, et al. Posthepatectomy liver failure: a definition and grading by the International Study Group of Liver Surgery

(ISGLS). Surgery. 2011;149(5):713-24.

http://doi.org/10.1016/j.surg.2010.10.001

24. Rahbari NN, Garden OJ, Padbury R, Maddern G, Koch M, Hugh TJ, et al. Post-hepatectomy haemorrhage: a definition and grading by the International Study Group of Liver Surgery (ISGLS). HPB (Oxford). 2011;13(8):528-35. http://doi.org/10.1111/j.1477-2574.2011.00319.x

25. Nordlinger B, Sorbye H, Glimelius B, Poston GJ, Schlag PM, Rougier P, et al. Perioperative FOLFOX4 chemotherapy and surgery versus surgery alone for resectable liver metastases from colorectal cancer (EORTC 40983): long-term results of a randomised, controlled, phase 3 trial. Lancet Oncol. 2013;14(:1208-1215.

http://doi.org/10.1016/S1470-2045(13)70447-9

26. Sandstrom P, Rosok BI, Sparrelid E, Larsen PN, Larsson AL, Lindell G, et al. ALPPS Improves Resectability Compared with Conventional Two-stage Hepatectomy in Patients with Advanced Colorectal Liver Metastasis: Results from a Scandinavian Multicenter Randomized Controlled Trial (LIGRO Trial). Ann Surg. 2018; 267:833-840.PMID - 28902669. http://doi.org/10.1097/SLA.0000000000002511

27. Wasan HS, Gibbs P, Sharma NK, Taieb J, Heinemann V, Ricke J, et al. First-line selective internal radiotherapy plus chemotherapy versus chemotherapy alone in patients with liver metastases from colorectal cancer (FOXFIRE, SIRFLOX, and FOXFIREGlobal): a combined analysis of three multicenter, randomised, phase 3 trials. Lancet Oncol. 2017; 18:1159-1171. http://doi.org/10.1016/S1470-2045(17)30457-6 